\title{
DISTRIBUIÇÃO ESPACIAL DO VALOR DA PRODUÇÃO DA SOJA NO RIO GRANDE DO SUL: DISTINTOS RETRATOS DE 2000 A 2010
}

Jessica de Lima da Vida Pellenz ${ }^{1}$ Mariza de Almeida ${ }^{2}$ Clailton Ataídes de Freitas ${ }^{3}$

Resumo: O objetivo do presente artigo é analisar as alterações ocasionadas pelo Boom das Commodities na distribuição espacial da produção da soja no estado do Rio Grande do Sul (RS), Brasil, através de análise exploratória de dados espaciais (AEDE), bem como identificar a formação de clusters nos anos de 2000, 2004, 2005 e 2010. Para tanto, foram utilizados dados secundários da Produção Agrícola Municipal, obtidos no site do Instituto Brasileiro de Geografia e Estatística (IBGE), em que se analisou o valor da produção da soja por meio da análise do índice de Moran. Os resultados encontrados sugerem que há autocorrelação espacial positiva entre os municípios, e que o boom teve efeitos distintos no curto e longo-prazo no que se refere aos municípios com elevada autocorrelação espacial.

Palavras-chave: Soja. Distribuição Espacial. Rio Grande do Sul.

\section{SPATIAL DISTRIBUTION OF VALUE OF SOYBEAN PRODUCTION IN RIO GRANDE DO SUL: DIFFERENT PORTRAITS FROM 2000 TO 2010}

Abstract: The objective of this paper is to analyze the changes caused by the Commodities Boom in the spatial distribution of soybean production in the State of Rio Grande do Sul, through Exploratory Spatial Data Analysis (ESDA), as well as to identify clusters formation in 2000, 2004, 2005 e 2010. For this, we used secondary data from Municipal Agricultural Production, obtained from the website of the Brazilian Institute of Geography and Statistics (IBGE), in which the value of soybean production was analyzed through the Moran index. The results suggest that there is positive spatial autocorrelation between cities, and that the boom had distinct short and long-term effects for municipalities with high spatial autocorrelation.

Keywords: Soybean. Spatial Distribution. Rio Grande do Sul.

\section{DISTRIBUCIÓN ESPACIAL DEL VALOR DE LA PRODUCCIÓN DE LA SOJA EN EL RIO GRANDE DO SUL: DISTINTOS RETRATOS DE 2000 A 2010}

Resumen: El objetivo del presente artículo es analizar los cambios ocasionados por el Boom de las Commodities en la distribución espacial de la producción de la soja en el estado de Rio Grande do Sul (RS), Brasil, através del análisis exploratorio de datos espaciales (AEDE), así como identificar la formación de clusters en los años $2000,2004,2005$ y 2010. Por lo tanto, se utilizaron datos secundarios de la Producción Agrícola Municipal, obtenidos en el sitio del Instituto Brasileño de Geografía y Estadística (IBGE), en que se analizó el valor de la producción de la

\footnotetext{
1 Universidade Federal de Viçosa, Departamento de Economia Rural, Viçosa, Brasil, jessipellenz@gmail.com, https://orcid.org/0000-0001-7091-0964

2 Universidade de São Paulo - Esalq, Departamento de Economia, Piracicaba, Brasil, mariza.de.almeida@hotmail.com, https://orcid.org/0000-0003-2910-8704

${ }^{3}$ Universidade Federal de Santa Maria, Departamento de Economia, Santa Maria, Brasil, Icv589@gmail.com, https://orcid.org/0000-0003-0754-3211
} 
producción soja por medio del análisis del índice de Moran. Los resultados encontrados sugieren que hay autocorrelación espacial positiva entre los municipios, y que el boom tuvo efectos distintos en el corto y largo plazo en lo que se refiere a los municipios con elevada autocorrelación espacial.

Palabras clave: Soja. Distribución Espacial. Rio Grande do Sul.

\section{Introdução}

No contexto internacional, o Brasil é considerado um dos maiores produtores de commodities, essa posição é resultado de vantagens provenientes dos fatores edafoclimáticos, culturais, ambientais e aos ganhos de produtividade que decorreram da incorporação de tecnologias de elevado padrão no cultivo das principais culturas. O desempenho do setor agropecuário tem impactos importantes no cenário econômico brasileiro, pois através desse setor se gera divisas de exportações, contribui para a recuperação da economia nos momentos de crise dos demais setores e, ainda possibilita a manutenção do poder de compra da população, via controle dos patamares de inflação.

Segundo Freitas e Sáfadi (2015), o Brasil ao reunir vantagens comparativas naturais e importantes avanços tecnológicos resultante de pesquisa e desenvolvimento (P\&D) em todas as etapas da produção agropecuária e política pública de apoio ao setor, principalmente, o crédito rural, tornou-se um dos principais provedores mundiais de alimento, tornando-se competitivo na produção e exportação de vários produtos, como o suco de laranja o açúcar, o tabaco, o algodão, a carne suína, o frango, boi gordo, o café, o etanol, o frango, o milho, o farelo de soja e, principalmente, a soja.

O setor agropecuário é notadamente imprescindível para a manutenção de bons resultados da balança comercial no Brasil. Segundo os dados disponíveis no Ministério da Indústria, Comércio Exterior e Serviços (MDIC, 2018), em 2016 a participação da soja na exportação total do Brasil foi de 10,43\%, já em 2017, a participação foi de $11,81 \%$, mostrando-se um dos produtos mais representativo nas exportações. O valor bruto da produção $(\mathrm{VBP})^{4}$ de soja no Brasil, em 2010, correspondia a 17\% do VBP agropecuária brasileiro, já em 2017 essa produção passou a representar $22 \%$. Ressalta-se, também, que dentre os diferentes tipos de

\footnotetext{
${ }^{4} \mathrm{O}$ valor bruto da produção (VBP) refere-se ao valor dos bens que são produzidos mesmo que estejam estocados ou tenham sido vendidos (FEIJÓ; RAMOS, 2013).
} 
lavouras do Brasil, a produção de soja representou 33\% do total, estas em sua maioria localizadas nas Regiões Sul e Centro-Oeste brasileiros (MAPA, 2018).

Um dos estados que mais produz soja, terceiro maior do país, é o Rio Grande do Sul. Sua estrutura agropecuária é caracterizada pela dinâmica nas exportações, pela diversificação das localidades, pela produção em agrupamento, pelo impacto nas cadeias produtivas, pela incorporação constante por tecnologia para aumentar a produtividade e por apresentar uma diversificação na pauta de produção. Além da soja, destacam-se a produção de milho e trigo, dentre outros. Nas regiões norte e noroeste do RS, o setor agropecuário é predominante, sendo que sua composição se caracteriza por pequenas e médias propriedades, e sua produção formada, basicamente, por lavouras mecanizadas de trigo e soja (ROCHA; PARRÉ, 2009).

O complexo de soja está entre as cinco atividades agropecuárias mais importantes do setor agropecuário gaúcho. Em 2017 sua participação no valor bruto da produção (VBP) agropecuário do Rio Grande do Sul foi de $53 \%$, sendo que a participação do estado no VBP agropecuário nacional foi de 10,6\%. A exportação de soja foi a mais importante, nos dois primeiros meses do ano de 2018 , no volume de exportação do agronegócio gaúcho, com o expressivo valor de US\$554,1 milhões. No mês de fevereiro de 2018, o total de soja embarcado foi de 517,9 mil toneladas. Em comparação a fevereiro de 2017 houve um crescimento de $476,9 \%$ no volume (FEE, 2018).

Ao interligar-se com os demais setores (efeito multiplicador, tanto a jusante quanto a montante), a cultura de soja gera valor agregado e emprego nas regiões onde é explorada. No Rio Grande do Sul, o setor agropecuário está entre as dez atividades que mais geram emprego. No ano de 2015, o setor empregou 87.736 pessoas. No ano de 2004 , a soja correspondia a $36 \%$ do valor da produção total das culturas temporárias e permanentes do Rio Grande do Sul. Sendo que a quantidade produzida em toneladas nesse período, representava $18,3 \%$ das lavouras do estado e a área plantada (ha) foi de $14 \%$. Ou seja, dentre as lavouras, a soja foi a que usou maior área. Salienta-se que a produção de soja, no ano de 2010, representou $24 \%$ do VBP agropecuário gaúcho, já no ano de 2017 correspondia a 36\%. Além disso, a produção de soja destaca-se entre os tipos de lavouras do RS, sua participação no ano de 2010 era 37\%, em 2017 passou para 53\% (MAPA, 2018). 
Cabe ressaltar também que $\circ$ Valor Adicionado Bruto $(\mathrm{VAB})^{5}$ do setor agropecuário gaúcho apresentou um aumento de 2000 para 2004, passando de $7 \%$ para $12 \%$ do VAB total do RS. Já nos anos de 2005 e 2010 passou a representar $7 \%$ e $8 \%$, respectivamente (FEE, 2018).

Dada a necessidade de melhor incorporação de tecnologia e compra de sementes na agricultura, em 2000, o RS foi o estado que mais obteve financiamentos a produtores e cooperativas (crédito rural no total), representando 16,71\% do total concedido ao país. Em 2004 essa participação passou para 17,27\%, em 2005 apresentou queda, representando 15,03\%, mas no ano de 2010, esse valor já estava mais alto, correspondendo a 16,69\% (BACEN, 2018). Ressalta-se ainda que em 2017, uma das principais lavouras que recebeu crédito rural (financiamento de custeio) foi a de soja (CONAB, 2018).

Estando o Rio Grande do Sul entre os maiores produtores de soja do Brasil e, sendo sua produção um dos principais motores do setor agropecuário, aponta-se o seguinte questionamento: houve alguma mudança na distribuição espacial da soja no estado do Rio Grande do Sul após o boom dos preços das commodities?

Para responder essa questão, delineiam-se como objetivos: Analisar as alterações ocasionadas pelo boom dos preços das commodities (iniciado em 2004) na distribuição espacial da produção de soja no estado do RS; e, identificar a formação de clusters através de uma análise exploratória de dados espaciais (AEDE) para os anos de 2000, 2004, 2005 e 2010, dado que esses anos representam, respectivamente, o que antecede o evento de aumento acentuado dos preços, o boom, e os períodos que o sucedem.

$O$ presente estudo foi organizado em seis seções, sendo a primeira constituída por esta introdução. A Seção 2 traz uma breve apresentação da estrutura agropecuária e do complexo de soja no Brasil e no Rio Grande do Sul no século XXI, ou seja, apresenta-se sua importância e sua evolução no decorrer dos anos. $\mathrm{Na}$ Seção 3 está a metodologia, em que se apresenta o método econométrico de análise exploratória de dados espaciais, assim como os dados utilizados. Na Seção 4 apresenta-se os resultados obtidos na presente pesquisa. Por último, na Seção 5, têm-se as principais conclusões.

${ }^{5} \mathrm{O}$ valor adicionado bruto (VAB) indica o quanto cada setor da economia contribui na formação do valor final de tudo que uma região produziu em um determinado período de tempo (FEE, 2018). 


\section{Complexo de soja no século XXI: Brasil e Rio Grande do Sul}

$\mathrm{Na}$ década de 60, o governo brasileiro tinha como objetivo impulsionar o crescimento da produção de commodities no País por meio de incentivos ao setor agropecuário (GREMAUD; VASCONCELLOS; TONETO, 2017). Com a criação da Empresa Brasileira de Pesquisa Agropecuária (EMBRAPA), em 1972, o agronegócio torna-se intensivo em conhecimento, devido aos investimentos em pesquisas e ao desenvolvimento de tecnologia nacional para a sustentabilidade desse setor. Além disso, a modernização da agricultura possibilitou o cultivo da soja em um menor ciclo produtivo, como também, estimulou o aumento da sua produção (VIEIRA FILHO, 2016).

A produção da soja se expandiu no Brasil, durante a década de 1960, primeiramente, nos estados do Rio Grande do Sul (RS), de Santa Catarina (SC) e do Paraná (PR), uma vez que as características climáticas da Região Sul propiciam as condições edafoclimáticas adequadas para o cultivo desse grão. Em 1970, a produção de soja desses três estados passou a corresponder a mais de $80 \%$ da produção brasileira, sendo o RS o maior produtor e o pioneiro na exportação dessa commodity (WARNKEN, 2000).

No período de 1980, o sucesso do cultivo de soja desses três estados, como também a expansão industrial e do mercado internacional, contribuíram para a disseminação da produção dessa commodity pela Região Centro-Oeste, que passou a corresponder a cerca de 90\% da produção do território nacional no ano de 1997. Além disso, durante os anos 80 com a desvalorização cambial, a produção agrícola no Brasil estava voltada às exportações (FEIJÓ, 2011).

De 1990 a 2001, a produção de commodities no Brasil apresentou situações distintas. Se, por um lado, a área cultivada (com cerca de 37 milhões de ha) permaneceu constante, por outro, a produção das atividades agrícolas experimentou um forte incremento produzindo, inicialmente, 57,8 milhões de toneladas e, posteriormente, 92,8 milhões de toneladas. Portanto, a nova dinâmica na produção possibilitou o aumento da produtividade, o que evidencia o quanto a agricultura foi fundamental para o crescimento econômico brasileiro (ARAÚJO, 2013).

Em 2003, com a valorização do preço das commodities no mercado externo e os investimentos em infraestrutura para a produção no setor agrícola, o Brasil vivenciou o chamado boom das commodities, que possibilitou a aceleração do crescimento do país, visto que ao longo da história brasileira esse ano foi 
considerado como o mais intenso e longo, tornando-se um fator importante para a expansão do agronegócio (BLACK, 2015). Como se pode observar na Tabela 1, em 2004, a quantidade produzida de soja brasileira aumentou em relação ao ano de 2000, já que, nesse ano, foram produzidas 32,82 milhões de toneladas, enquanto em 2004, foi observada uma produção de 49,54 milhões de toneladas, evidenciando forte crescimento do cultivo da soja no País.

Em 2005, a produção do complexo de soja no território continuou crescendo, produzindo cerca de 51,18 milhões de toneladas, uma vez que tanto a quantidade demandada, quanto o preço internacional aumentou, contribuindo desta forma para a expansão econômica no País, como também, mudou a política de geração de saldos comerciais das exportações de produtos primários (DELGADO, 2005).

A produtividade do setor agrícola continuou crescendo até 2008, mas a partir desse ano, a produção atingiu o seu ponto máximo, devido à desvalorização do preço das commodities causada pela crise financeira mundial (BLACK, 2015). Mesmo com essas dificuldades, após a crise de 2010, o Brasil atingiu uma produção de 68,75 milhões de toneladas. $\mathrm{E}$, em 2011, a produção agrícola continuou crescendo devido a grande quantidade demandada no mercado internacional, principalmente, pela China. Assim, a crise ocorrida em 2008 não significou uma desvalorização dos preços commodities brasileira, pelo contrário, em 2011 o setor agrícola ainda apresentava um expressivo crescimento (BLACK, 2015).

A produção média anual de soja entre 1990 e 2012, expandiu em cerca de 6,35\%, ou seja, passou de 20 milhões de toneladas para, aproximadamente, 66 milhões de toneladas. Esse desempenho se deve muito ao aumento na área plantada, ao desenvolvimento de novas variedades de soja e a grande demanda mundial, principalmente, da China (CASTILHOS; BRAGANHOLO, 2014). Porém, a produção da soja sofre muitas oscilações, tendo momentos bons, como o boom em 2004, em que a demanda era alta e os preços favoráveis e, momentos de frustrações, como em 1991, 2005 e 2008, que foram causados, principalmente, por problemas climáticos e pela crise econômica (TRENNEPOHL; PAIVA, 2011).

No entanto, grandes investimentos em tecnologia voltadas ao setor agropecuário, sustentado na maior parte das vezes pelo crédito rural, tem contribuído para a expansão da safra agrícola na maior parte dos estados brasileiros. Nesse contexto, destaca-se o Rio Grande do Sul, um dos estados que mais recebeu crédito e incentivos para aumentar a produção da soja. O estado tem grande importância na oferta de produtos primários, como o arroz e a soja. Este 
último com expressiva participação nas exportações de commodities do País. No território gaúcho destinado a exploração da atividade agropecuária, aproximadamente, $90 \%$ da área plantada é voltada às lavouras permanentes (produção de grãos), isso ocorreu, principalmente após o crescimento da demanda externa, pelos altos preços da commodity soja no mercado internacional e pelos investimentos públicos (FEE, 2018). 
Tabela 1 - Informações sobre a produção de soja no Brasil e no Rio Grande do Sul para os de 2000, 2004, 2005 e 2010

\begin{tabular}{|c|c|c|c|c|c|c|c|c|}
\hline \multirow{2}{*}{ Informação } & \multicolumn{2}{|c|}{ Ano 2000} & \multicolumn{2}{|c|}{ Ano 2004} & \multicolumn{2}{|c|}{ Ano 2005} & \multicolumn{2}{|c|}{ Ano 2010} \\
\hline & RS & Brasil & RS & Brasil & $\mathrm{RS}$ & Brasil & $\mathrm{RS}$ & Brasil \\
\hline $\begin{array}{l}\text { Área Colhida } \\
\text { (ha) }\end{array}$ & 3.001 .836 & 13.656 .771 & 3.968 .530 & 21.538 .990 & 3.733 .822 & 22.948 .874 & 4.013 .616 & 23.327.296 \\
\hline $\begin{array}{l}\text { Área Plantada } \\
\text { (ha) }\end{array}$ & 3.030 .556 & 13.693 .677 & 3.984 .337 & 21.601 .340 & 4.179 .272 & 23.426 .756 & 4.021 .778 & 23.339.094 \\
\hline $\begin{array}{l}\text { Quantidade } \\
\text { Produzida (t) }\end{array}$ & 4.783 .895 & 32.820 .826 & 5.541 .714 & 49.549 .941 & 2.444 .540 & 51.182 .074 & 10.480 .026 & 68.756 .343 \\
\hline $\begin{array}{l}\text { Rendimento } \\
\text { Médio (kg/ha) }\end{array}$ & 1,594 & 2,403 & 1,396 & 2,300 & 655 & 2,230 & 2,611 & 2,947 \\
\hline Valor da & & & & & & & & \\
\hline $\begin{array}{l}\text { Produção (em } \\
\text { R\$ mil) }\end{array}$ & 1.385 .502 & 8.658 .735 & 3.804 .582 & 32.627 .677 & 1.161 .908 & 21.750 .332 & 6.331 .727 & 37.332 .815 \\
\hline $\begin{array}{l}\text { Valor } \\
\text { Adicionado } \\
\text { Bruto a }\end{array}$ & & & & & & & & \\
\hline $\begin{array}{l}\text { Preços } \\
\text { Básicos da } \\
\text { Agropecuária } \\
\text { (em R\$ mil) }\end{array}$ & 5.983 .469 & 572.410 .00 & 12.759 .034 & 110.912 .703 & 8.143 .541 & 100.957 .547 & 17.162 .698 & 159.932 .000 \\
\hline Exportações & & & & & & & & \\
\hline $\begin{array}{l}\text { da Soja (em } \\
\text { US\$ FOB) }\end{array}$ & 265.815 .629 & 2.187 .878 .569 & 631.760 .586 & 5.394 .906 .561 & 107.779 .066 & 5.345 .047 .155 & 1.782 .456 .162 & 11.042 .999 .979 \\
\hline
\end{tabular}

Fonte: Elaborado pelos autores com base na FEE (2018), IBGE (2018) e ALICE WEB (2018). `Valores a preços correntes. 
A cultura de soja tem grande influência na economia gaúcha e, consequentemente, na economia brasileira, de acordo com a Secretaria de Planejamento, Governança e Gestão do RS (2017), o Brasil é o segundo maior produtor mundial de soja, superado apenas pelos Estados Unidos. Atualmente, tem concentrado a produção do grão de soja nas Regiões Centro-Oeste e Sul, sendo que os estados que apresentaram maior produção são o Mato Grosso, Paraná e Rio Grande do Sul, que em conjunto, representam cerca de $60 \%$ da produção brasileira (Figura 1). A área plantada de soja em mil hectares em 2013/14 foi de 30.173 e, em $2016 / 17$ foi de 33.909. Sendo que a produção de soja do Brasil em toneladas passou de 86.121 em 2014 para 114.075 em 2015 (CONAB, 2018).

Figura 1 - Mapa da produção da Soja no Brasil

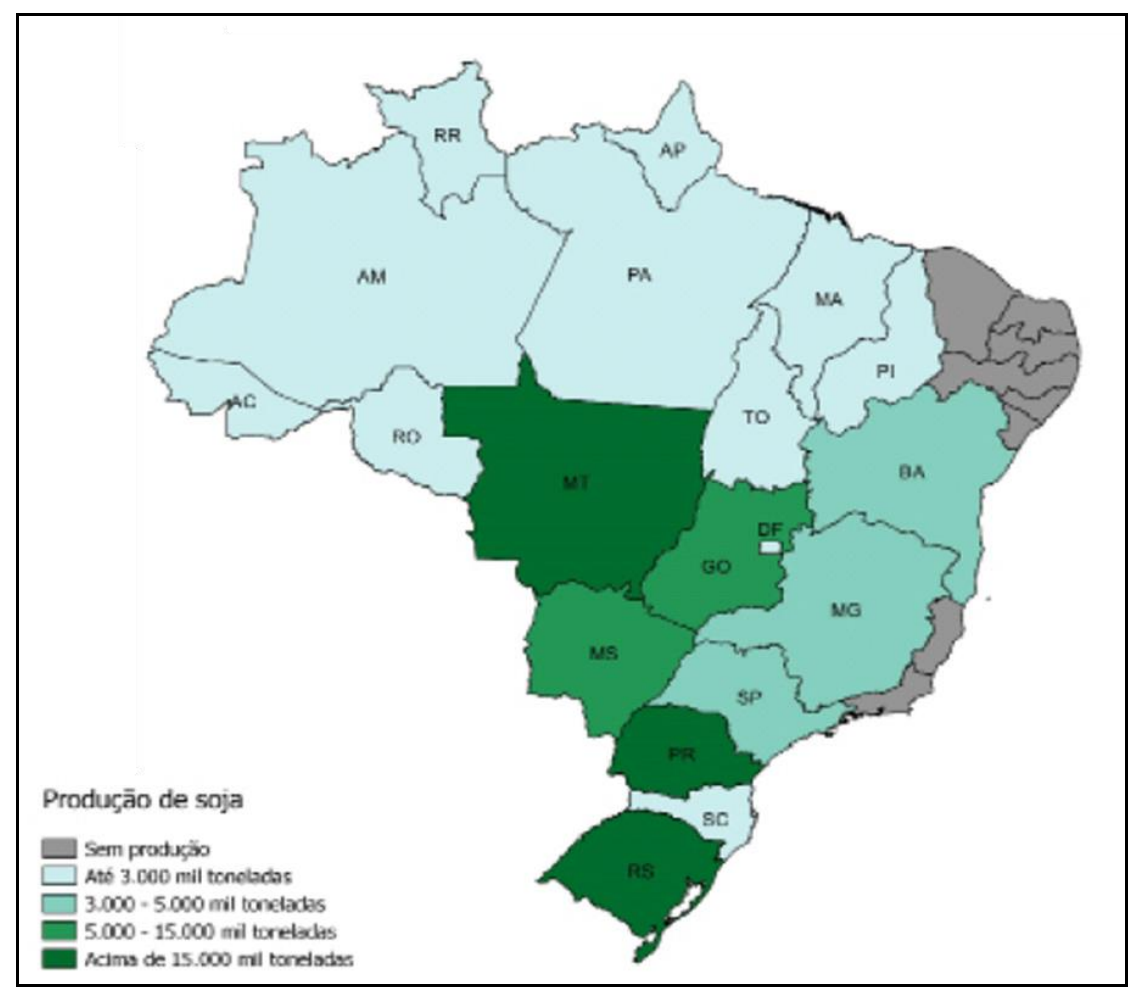

Fonte: CONAB (2018).

O Rio Grande do Sul possui, em média, uma produção total de 18,71 milhões de toneladas, que representa o melhor desempenho do estado nos últimos anos, apesar de manter a produtividade da safra dos anos anteriores (CONAB, 2018). A estrutura agropecuária do RS, de acordo com Rocha e Parré (2009), é caracterizada por haver dinâmica nas exportações, pela diversificação das localidades, pela produção em agrupamento e por apresentar uma diversificação na pauta de produção, como soja, milho, trigo, entre outros. O autor ressalta que esse setor 
agropecuário apresenta significativa participação no PIB gaúcho, sendo que, nos últimos anos, foi o responsável pelo bom desempenho econômico do estado.

O setor agropecuário gaúcho foi responsável por 9,38\% do total do VAB do RS em 2015. De acordo com a Secretaria de Planejamento, Governança e Gestão do RS (2017), a atividade agropecuária tem grande importância no estado, tendo influência sobre outros setores da economia por meio da cadeia produtiva, ou seja, antes da porteira (fornecedores de insumos, máquinas e equipamentos), dentro da porteira (produtor) e depois da porteira (empresas e cooperativas responsáveis pelo processamento e distribuição da produção).

A produção de soja, considerada uma das principais culturas do RS, está presente em propriedades pequenas, médias e grandes, e em praticamente, todas as regiões do estado. Assim, os próximos tópicos deste trabalho são destinados a uma melhor visualização da distribuição do valor da produção de soja no RS nos últimos anos, em especial nos anos de 2000, 2004, 2005 e 2010.

\section{Metodologia}

Explorando as ferramentas da econometria espacial

A econometria espacial difere da tradicional por incorporar variáveis que captam os efeitos da autocorrelação e heterocedasticidade espaciais do modelo. Dessa maneira, possibilita estimar se uma variável de determinada localidade sofre alguma influência da mesma variável de uma localidade próxima. Para analisar-se os efeitos espaciais da produção de soja no Rio Grande do Sul, se fazem necessários esclarecimentos a respeito de conceitos importantes e que são elucidados ao longo da presente seção.

O objetivo da econometria espacial é observar se há autocorrelação espacial, ou seja, se a variável de interesse de uma localidade $i$ tem efeito sobre o valor da mesma variável de localidades vizinhas $j$. Segundo Almeida (2012), com dados na forma de cross-section a matriz variância-covariância pode ser definida como:

$$
\operatorname{Cov}\left(y_{i}, y_{j}\right)=E\left(y_{i}, y_{j}\right)+E\left(y_{i}\right) E\left(y_{j}\right) \neq 0 \quad \text { para } \quad i \neq j
$$


A matriz referida na equação (1) tem dimensão $(n \times n)$ e contém $\left(n^{2}-n\right)$ elementos de covariância. Existem duas abordagens para mensurar a dependência espacial, a primeira é uma abordagem direta da Geoestatística, em que os elementos são ordenados em pares de observações e classificados pela distância geográfica que os separa. A segunda é a abordagem paramétrica, a qual inviabiliza a estimação dos termos de covariância da matriz, já que se tem um número muito grande de interações entre as localidades.

O presente artigo pautará sua análise na segunda abordagem, e para tanto, necessita que os dados espaciais estejam representados na forma matricial, sendo que as interações resultantes da autocorrelação espacial estarão expostas em uma matriz de ponderação espacial $W$. Conforme Anselin (1998), a matriz $W$ tem dimensão $n \times n$ e estabelece valores iguais à unidade às variáveis que possuam dependência espacial com seus vizinhos, e para os sem vizinhos, atribui-se o valor zero. Ou seja, $w_{i j}=1$ quando os municípios $i$ e $j$ forem vizinhos e $w_{i j}=0$ em caso contrário. Essa matriz de pesos binários é construída com a ideia de vizinhança baseada na contiguidade, ou seja, duas regiões são consideradas contíguas se partilharem de fronteira física.

Para construir a matriz a matriz de ponderação, foram realizadas análises de quatro convenções de contiguidade, "Rainha 1", "Rainha 2", "Torre" e "Vizinhos mais próximos", as quais são descritas por Almeida (2012).

Após, criada a matriz de ponderação $W$, é necessário verificar se os dados apresentam dependência e heterogeneidade espacial. A análise exploratória de dados espaciais (AEDE) permite ao pesquisador conhecer mais sobre os dados utilizados na pesquisa. Conforme Almeida (2012, p. 102), a AEDE "é a coleção de técnicas para descrever e visualizar distribuições espaciais, identificar localidades atípicas (...) e descobrir padrões de associação espacial". Através dessa análise é possível reproduzir medidas de autocorrelação espacial global e local, além de investigar os efeitos espaciais e suas influências.

Silva (2013) destaca que o procedimento de AEDE se inicia pela constatação de aleatoriedade dos dados, ou seja, que as variáveis analisadas são espacialmente dependentes entre as localidades estudadas. Caso se constate que os dados são aleatórios, não faz sentido continuar a análise com econometria espacial, pois o valor da variável em uma localidade não depende do valor dessa mesma variável nos municípios vizinhos. Para averiguar a existência de aleatoriedade dos dados 
espaciais se utilizam índices que medem a autocorrelação espacial global e autocorrelação espacial local.

Para verificar a autocorrelação espacial global, recorre-se ao Índice de Moran, o qual é representado pelas equações (2) e (3):

$$
I=\frac{n}{s_{0}} \frac{\sum_{i} \sum_{j} w_{i j} z_{i} z_{j}}{\sum_{i=1}^{n} z_{i}^{n}}
$$

Ou na forma matricial:

$$
I=\frac{n}{S_{0}} \frac{z l W z}{z l z}
$$

em que l é o índice de Moran, $n$ é o número de localidades analisadas, $z$ representa os valores das variáveis de interesse padronizadas, $W z$ indica os valores médios da variável de interesse padronizada nos vizinhos, definidos conforme a matriz de ponderação $W, w_{i j}$ representa a forma como a localidade $i$ está espacialmente relacionada com a localidade $j, s_{o}$ é um escalar igual à soma de todos os elementos de W.

O I de Moran tem um valor esperado de -[1/(n-1)]. O valor calculado de I deve ser igual ao seu valor esperado dentro dos limites de significância estatística se $Y_{i}$ for independente dos valores nas localidades vizinhas. Valores de I maiores do que o valor esperado indicam autocorrelação positiva, enquanto se forem menores, há autocorrelação negativa (Almeida, 2012). Para verificar a significância do I de Moran, assume-se que a variável padronizada $Z(I)$ seja dada por:

$$
Z(I)=[I-E(I)] / D P(I)
$$

em que, $E(I)$ e $D P(I)$ representam o valor esperado e o desvio padrão de $I$.

O I de Moran fornece três informações importantes para a análise dos dados. O nível de significância revela se os dados são distribuídos aleatoriamente. O sinal positivo do índice aponta que os dados estão concentrados através das localidades e, se negativo, indica a dispersão dos dados. A magnitude da estatística fornece a força da autocorrelação espacial. Quanto mais perto de 1, mais forte é a concentração, e quanto mais perto de -1 , mais dispersos os dados. 
Para verificar a autocorrelação espacial local, se utiliza o I de Moran local, o qual tem a capacidade de analisar regimes de associação espaciais diferenciados, porque produzem um valor específico para cada área. A equação (5) representa o coeficiente / de Moran.

$$
I_{i}=z_{i} \sum_{j=1}^{n} w_{i j} z_{j}
$$

Conforme Almeida (2012), o cálculo de $I_{\bar{i}}$ só abrange os vizinhos da observação $i$, definidos conforme uma matriz de pesos espaciais. Para que $I_{i}$ seja um indicador de autocorrelação espacial, é necessário que:

$$
I_{i}=\sum_{i} z_{i} \sum_{j} w_{i j} z_{j}=\sum_{i} \sum_{j} w_{i j} z_{i} z_{j}
$$

Segundo Vidigal (2009), sob o pressuposto da aleatoriedade o valor esperado da estatística I de Moran local é dada por $E\left(I_{i}\right)=\frac{-w i}{n-1}$, em que wi é o somatório dos elementos da linha da matriz $W$.

Outra maneira de interpretar a estatística de Moran é através do diagrama de dispersão de Moran, no qual é possível visualizar a correlação linear entre $z$ e Wz no gráfico. O coeficiente I de Moran é dado pela inclinação da curva de regressão de Wz contra z. Na Figura 2, é possível verificar que o diagrama possui quatro quadrantes. $O$ primeiro quadrante, baixo-alto (BA), representa um grupo em que uma localidade qualquer, com baixo valor da variável de interesse, é circundada por localidades com alto valor. No quadrante alto-alto (AA) as localidades exibem altos valores da variável de interesse e está rodeada por localidade com valores altos. $O$ quadrante baixo-baixo (BB) refere-se ao grupo de associação espacial com baixo valor e está rodeado por grupos também de valor baixo. O quarto quadrante, altobaixo $(A B)$, mostra o agrupamento no qual o valor da variável de interesse é alto, mas está circundado por localidades com valor baixo (ALMEIDA, 2012). 
Figura 2 - Exemplo diagrama de dispersão de Moran

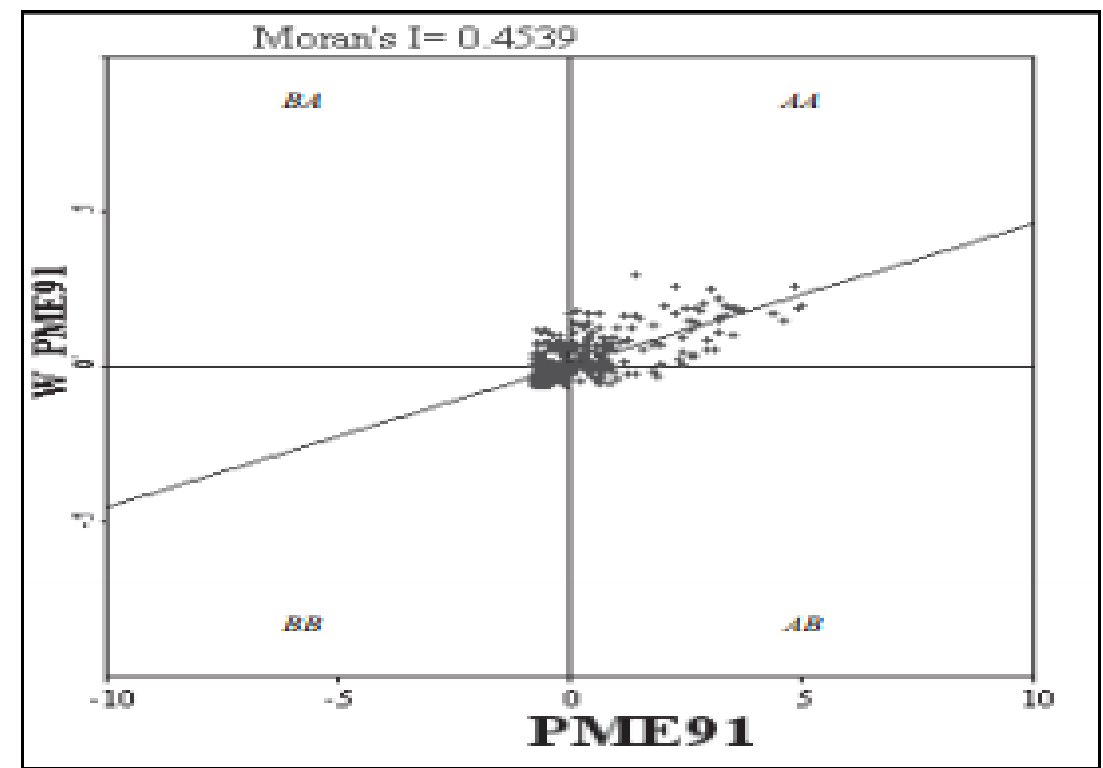

Fonte: Almeida (2008).

Desse modo, as localidades inseridas nos quadrantes 1 e 3 demonstram pontos com associação espacial positiva, ou seja, o local e a média da vizinhança apresenta valores parecidos. As regiões com essas características formam clusters com valores similares. Por sua vez, os quadrantes 2 e 4, apresentam autocorrelação espacial negativa (SILVA, 2013).

As variáveis e as fontes dos dados

A base de dados da presente pesquisa é composta pela variável valor produção da soja, em mil reais, dos quatrocentos e noventa e seis municípios do Rio Grande do Sul, contidos na base cartográfica disponibilizada pela FEE. Essa variável foi obtida no site no IBGE, na parte que relaciona a produção agrícola municipal (PAM - Tabela 5457), para os anos de 2000, 2004, 2005, 2010.

No IBGE o valor da produção é uma variável calculada pela média ponderada das informações de quantidade e preço médio pago ao produtor, de acordo com os períodos de colheita e comercialização de cada produto. As despesas de frete, taxas e impostos não são incluídas no preço. Nesta pesquisa, os valores foram corrigidos para valores correntes de 2015, pelo Índice Geral de Preços - Disponibilidade Interna (IGP-DI) da Fundação Getúlio Vargas (FGV), obtido no Banco Central do Brasil. 
Para fins de comparação, os quatro períodos foram utilizados para verificar de que forma se distribuía espacialmente o VBP da produção de soja no período que antecedeu o boom das commodities, utilizaram-se dados do ano de 2000. O VBP de 2004 serve como balizador do trabalho, identificado como ano em que teve início o ciclo de elevação nos preços dos produtos agrícolas. Para detectar as alterações ocorridas no período que sucede o boom foram analisados os anos de 2005, para verificar as alterações de curto-prazo, e 2010, visando detectar as variações em longo-prazo.

Para analisar os dados e construir os mapas, utilizou-se o geocódigo e o shapefile 2007-2008 fornecido pela Fundação de Economia e Estatística (FEE), por meio dos softwares GeoDa e Qgis 3.0.

\section{Análise dos Resultados}

A Figura 3 ilustra a distribuição espacial do valor da produção de soja no Rio Grande do Sul nos anos de 2000, 2004, 2005 e 2010. O mapa do ano de 2000 retrata a distribuição espacial do VBP da soja no estado no período que precede o boom das commodities; o mapa de 2004 demonstra as alterações no valor da produção ocorridas no ano em que foi deflagrada a alta acentuada nos preços; e os demais como tal variável se comportou no espaço produtivo após o referido evento.

Para fins de análise, o ano de 2005 foi utilizado para demonstrar as alterações no curto prazo e 2010 denota as variações no longo prazo. Segundo Serigati (2013), no curto prazo, os produtores agrícolas percebem os impactos de maneira mais forte, tanto em se tratando de choques positivos, quanto negativos. Entretanto, no longo prazo, as tendências originais da atividade agrícola são retomadas, a menos que alguma mudança estrutural tenha sido estabelecida. 
Figura 3 - Distribuição do valor da produção de soja do Rio Grande do Sul no ano de 2000, 2004, 2005 e 2010 (Mil reais/ $\mathbf{K m}^{2}$ )

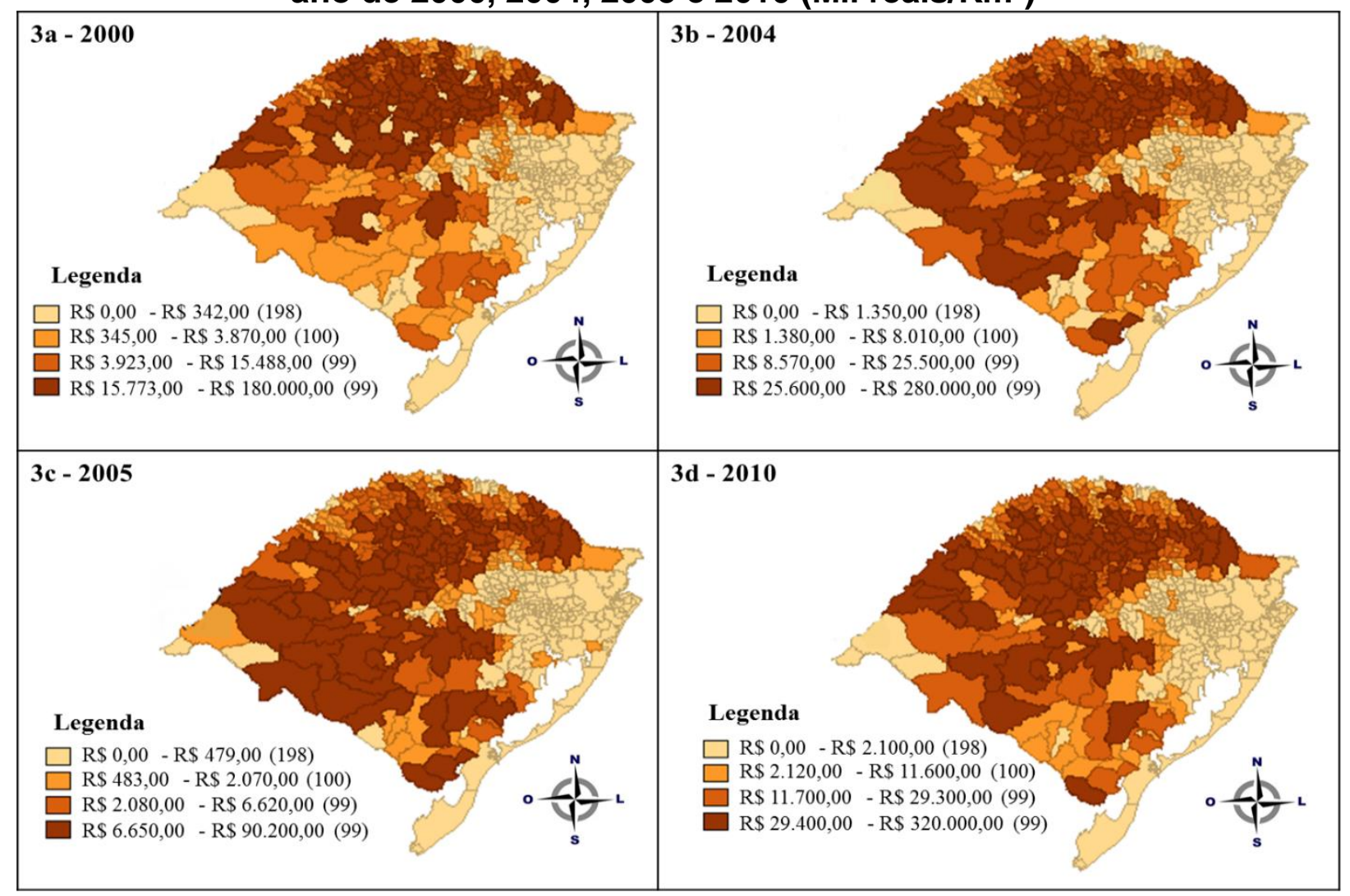

Fonte: Elaboração dos autores.

Percebe-se que, em 2000, os municípios que detinham maiores VBP estavam concentrados, principalmente, nas regiões norte e noroeste, enquanto que a maioria dos municípios com menores valores foram observados em toda a faixa litorânea e na região leste do estado. Após o boom das commodities, em 2004, nota-se que há um espraiamento dos municípios com maiores VBP, especialmente, para as regiões da fronteira oeste e sudoeste. Ademais, pode-se inferir que vários municípios do estado tiveram seu VBP aumentado do ano de 2000 para 2004, haja vista as faixas mais escuras na Figura $3 \mathrm{~b}$.

A análise de curto prazo (Figura $3 c$ ) permite verificar que o espraiamento de grandes valores de VBP foi intensificado no ano que sucedeu o boom, tendo agregado municípios em quase todas as regiões do estado. Entretanto, no longo prazo, evidenciou-se a retração dos municípios com VBP alto, retornando a patamares semelhantes a 2004, o que aponta para um efeito temporário do boom das commodities na produção de soja no estado. Essa observação corrobora com Serigati (2013) no que diz respeito à agricultura experimentar fortes impactos no curto prazo e retomar seus padrões anteriores no longo prazo. 
Para verificar se os municípios vizinhos apresentam semelhança entre si, procedeu-se o diagnóstico do índice global de Moran, o qual permite visualizar a autocorrelação espacial, mostrando a defasagem espacial da variável VBP no eixo vertical e essa mesma variável, mas sem defasagem no eixo horizontal. Conforme abordado no subitem 2.1.2, haverá autocorrelação espacial positiva quando o I de Moran Global exceder o valor crítico, ou valor esperado de Moran $E(I)=-0,00202$. $\mathrm{Na}$ Tabela 1 são relacionados os Índices de Moran para a variável VBP utilizando diferentes tipos de matrizes de ponderação espacial.

Tabela 1 - Índice de Moran para Valor da Produção

\begin{tabular}{|c|c|c|c|c|}
\hline Convenção & 2000 & 2004 & 2005 & 2010 \\
\hline Rainha 1 & $0,468^{\star \star \star}$ & $0,535^{\star \star \star}$ & $0,502^{\star \star \star}$ & $0,549 * * *$ \\
\hline Rainha 2 & $0,345^{\star \star \star}$ & $0,338^{\star \star *}$ & $0,269^{* \star *}$ & $0,345^{\star \star \star}$ \\
\hline Torre & $0,344^{\star \star *}$ & $0,338^{\star * \star}$ & $0,271^{* \star *}$ & $0,345^{\star \star \star}$ \\
\hline Vizinhos mais Próximos & $0,297^{* * *}$ & $0,371^{* * *}$ & $0,333^{\star \star *}$ & $0,397^{* * *}$ \\
\hline
\end{tabular}

Fonte: Elaboração dos autores.

${ }^{* \star \star}$ Estatisticamente significativos a $1 \%$.

Os resultados dispostos na Tabela 1 demonstram que os quatro critérios de vizinhança utilizados validam a hipótese de autocorrelação espacial entre os municípios do estado a $1 \%$ de significância. Percebe-se que há autocorrelação espacial positiva entre os vizinhos de primeira e segunda ordem, ou seja, um município possui similaridade com os vizinhos que fazem fronteiras geográficas consigo e com os vizinhos destes. Todas as convenções de contiguidade utilizadas revelaram um índice global de Moran positivo, portanto, a autocorrelação entre os municípios ocorre no mesmo sentido.

Para realizar a AEDE, foi utilizada a convenção "Rainha" por ter obtido índice de Moran maior do que as demais, indicando maior autocorrelação espacial entre os municípios. A Figura 4 fornece melhor visualização dos índices para os quatro anos estudados. Percebe-se que há a autocorrelação espacial positiva entre os municípios do Rio Grande do Sul, visto que a trajetória da linha do índice é crescente. A autocorrelação positiva evidencia uma similaridade entre os municípios vizinhos, ou seja, municípios com alto valor de produção localizam-se próximos a municípios com a mesma característica. 
Figura 4 - Índices de Moran para VBP Soja nos anos de 2000, 2004, 2005 e 2010

\begin{tabular}{|c|c|c|c|}
\hline $4 a-2000$ & $4 b-2004$ & $4 c-2005$ & 4d - 2010 \\
\hline 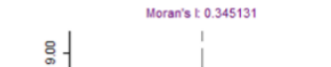 & 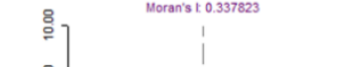 & Morans to 0286916 & s. \\
\hline$\therefore$ & $=8-$ & 8 & 8 \\
\hline 8 & :- & 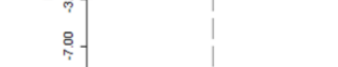 & 8 \\
\hline 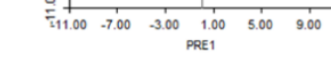 & 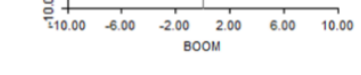 & 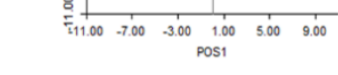 & 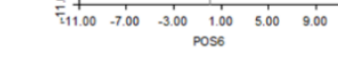 \\
\hline
\end{tabular}

Fonte: Elaboração dos autores.

Na Figura 5 é apresentado o mapa de agrupamento (cluster) para o VBP da soja para o ano de 2000. Para essa análise utilizou-se a convenção "Rainha" para a matriz de ponderação. Observou-se que existem dois clusters bem definidos, um alto-alto (vermelho) e um baixo-baixo (azul). O cluster alto-alto indica os municípios que obtiveram autocorrelação alta para o VBP de soja, ou seja, os municípios situados nessa faixa obtiveram maiores VBP do que o restante do estado. Em contrapartida, o cluster baixo-baixo revela os municípios que apresentaram menor autocorrelação entre si, portanto, tiveram VBP mais baixos do que os demais municípios do estado, o que está de acordo com a característica da região em que está locado, predominantemente litoral e região metropolitana de Porto Alegre, sendo esta última conhecidamente urbana.

Figura 5 - Mapa Clusters para o valor da produção da soja (Mil reais $/ \mathrm{Km}^{2}$ ) no estado do Rio Grande do Sul, para o ano de 2000

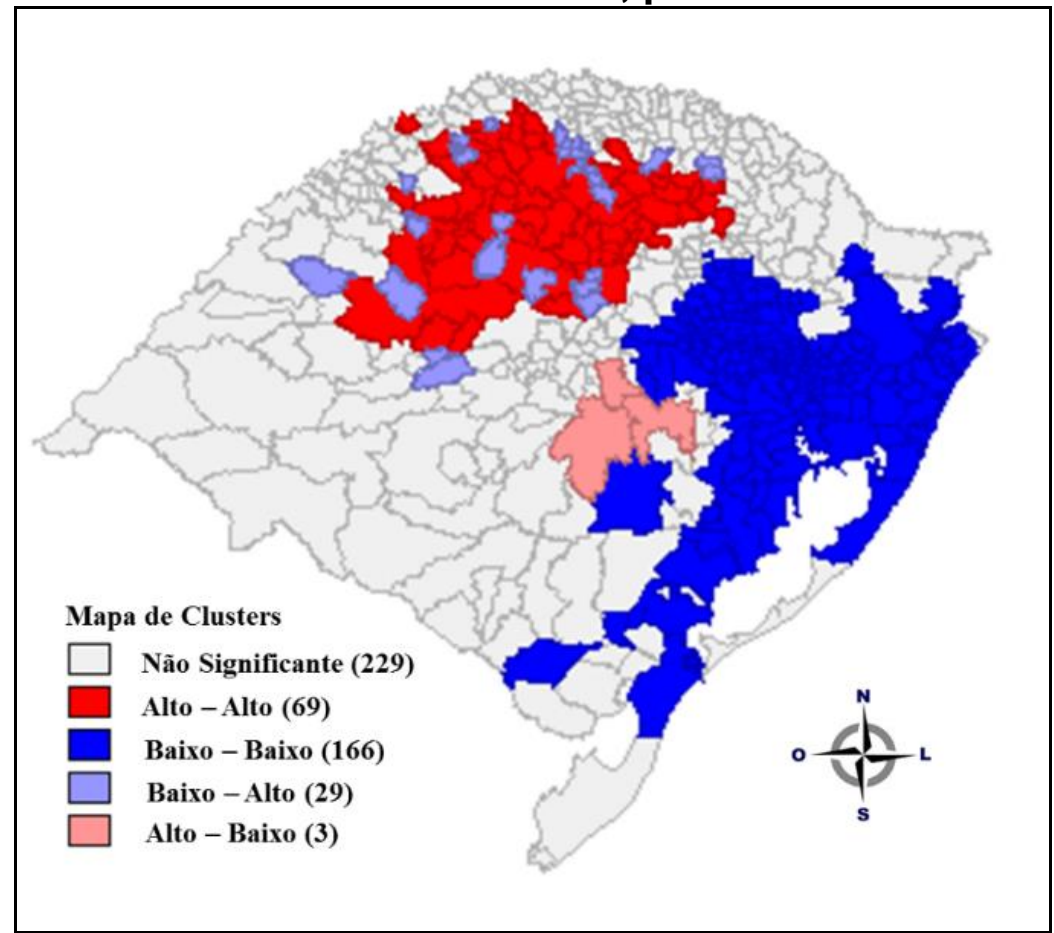

Fonte: Elaboração dos autores. 
Para se avaliar possíveis alterações determinadas pelo boom das commodities, procedeu-se a análise de agrupamentos para o ano de 2004, a qual está representada pela Figura 6. Nota-se que ainda predominam dois clusters (altoalto e baixo-baixo), entretanto, poucos municípios foram incorporados aos agrupamentos existentes no ano de 2000. Além da adição de alguns municípios na faixa centro-oeste, centro-norte e sudeste ao cluster alto-alto, notou-se uma retração no cluster de baixa autocorrelação espacial.

\section{Figura 6 - Mapa Clusters para o valor da produção da soja (Mil reais/ $\mathrm{Km}^{2}$ ) no estado do Rio Grande do Sul, para o ano de 2004 (Boom)}

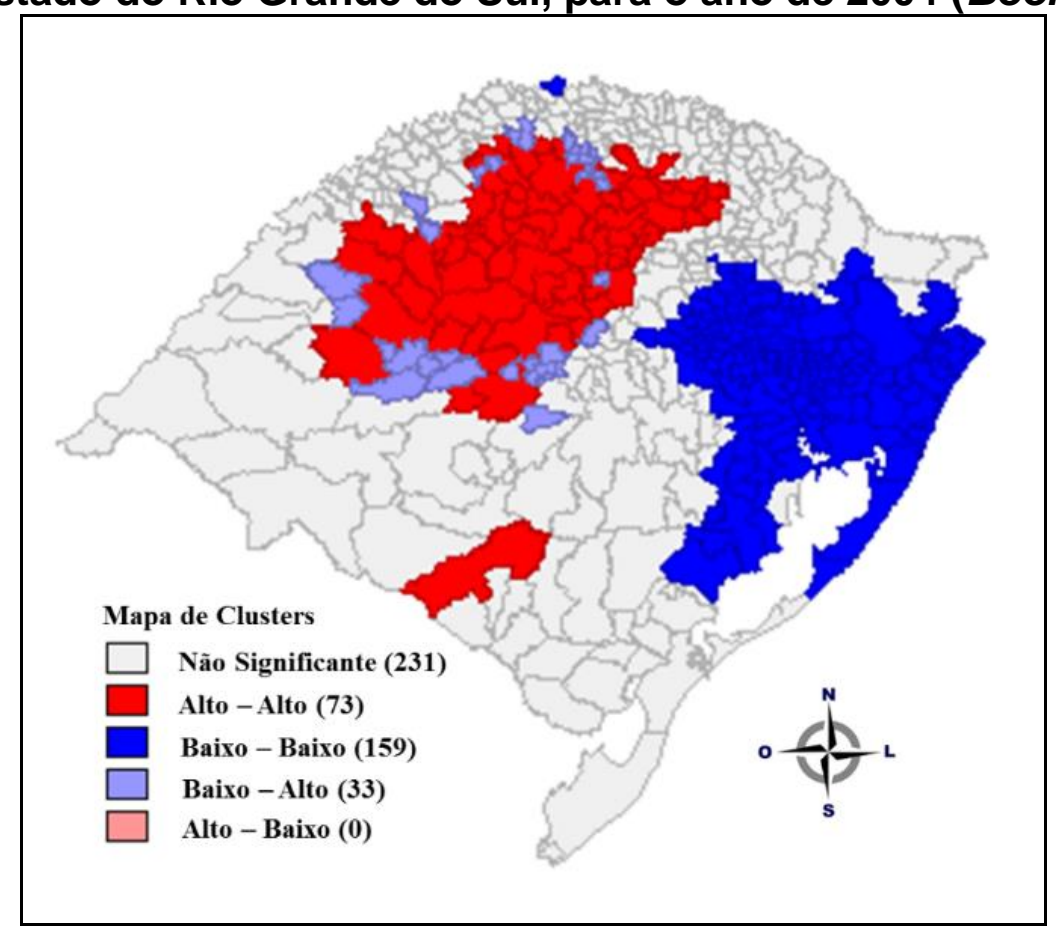

Fonte: Elaboração dos autores.

A Figura 7 retrata a análise de agrupamentos para o ano de 2005, visando identificar possíveis alterações de curto prazo ocasionadas pelo boom. No ano que sucede as altas nos preços das commodities verificou-se o espraiamento do cluster alto-alto, incorporando municípios da fronteira oeste, centro-oeste e nordeste, confirmando a análise realizada da figura $2 \mathrm{c}$, no que se refere ao aumento no número de municípios com alto VBP. Quanto ao cluster baixo-baixo, percebeu-se que houve outra contração no número de municípios, de 150 em 2004 para 145 em 2005. Assim sendo, no curto prazo, pode-se dizer que o boom das commodities favoreceu a produção de soja no Rio Grande do Sul, destarte o aumento no número de municípios

com altos valores de VBP. 
Figura 7 - Mapa Clusters para o valor da produção da soja (Mil reais/Km²) no estado do Rio Grande do Sul, para o ano de 2005

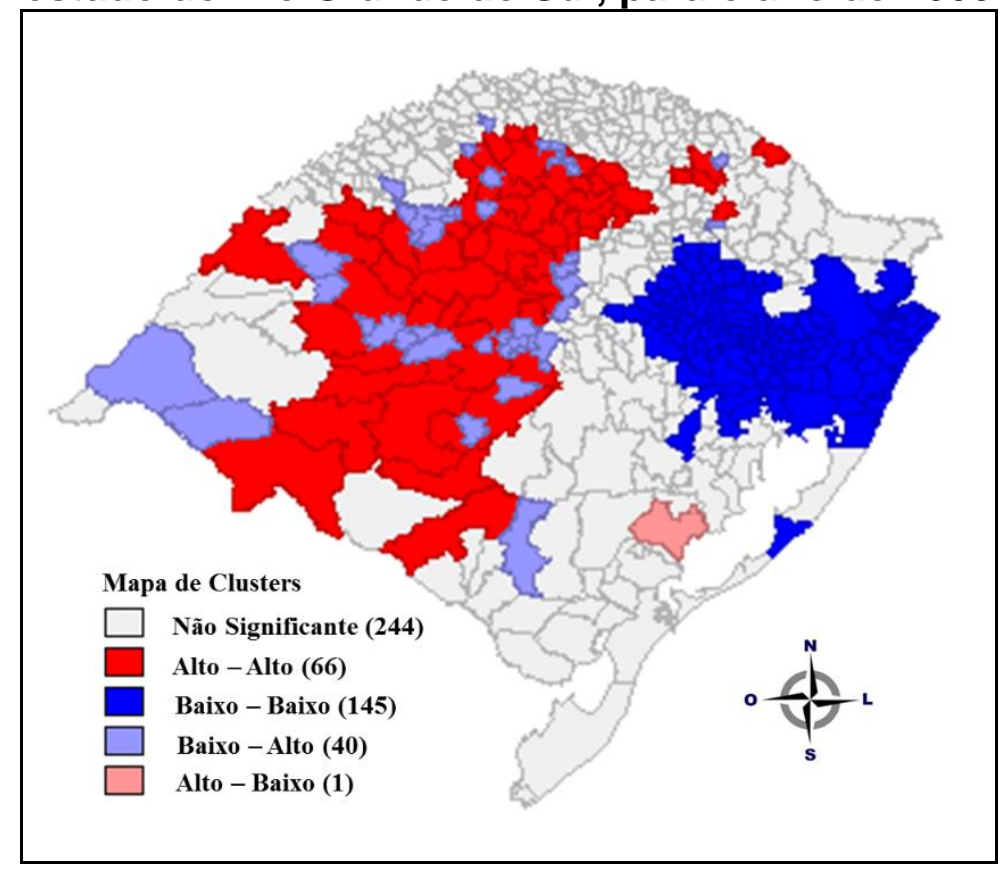

Fonte: Elaboração dos autores.

A Figura 8 representa a distribuição espacial do valor da produção de soja no Rio Grande do Sul para o ano de 2010. Passados seis anos das primeiras manifestações de aumento acentuado nos preços das commodities, a expansão da produção de soja para outras regiões do estado parece ter sido abrandada. Percebe-se que os municípios com autocorrelação elevada concentraram-se novamente em regiões próximas àquelas ocupadas no ano de 2000 , entretanto, mais municípios passaram a integrar este cluster, em comparação ao período que precedeu a alta dos preços. Já o cluster baixo-baixo retornou aos padrões verificados em 2000, revelando que, no longo prazo, restabeleceu-se a pouca vocação desses municípios na produção de soja. 
Figura 8 - Mapa Clusters para o valor da produção da soja (Mil reais/Km²) no estado do Rio Grande do Sul, para o ano de 2010

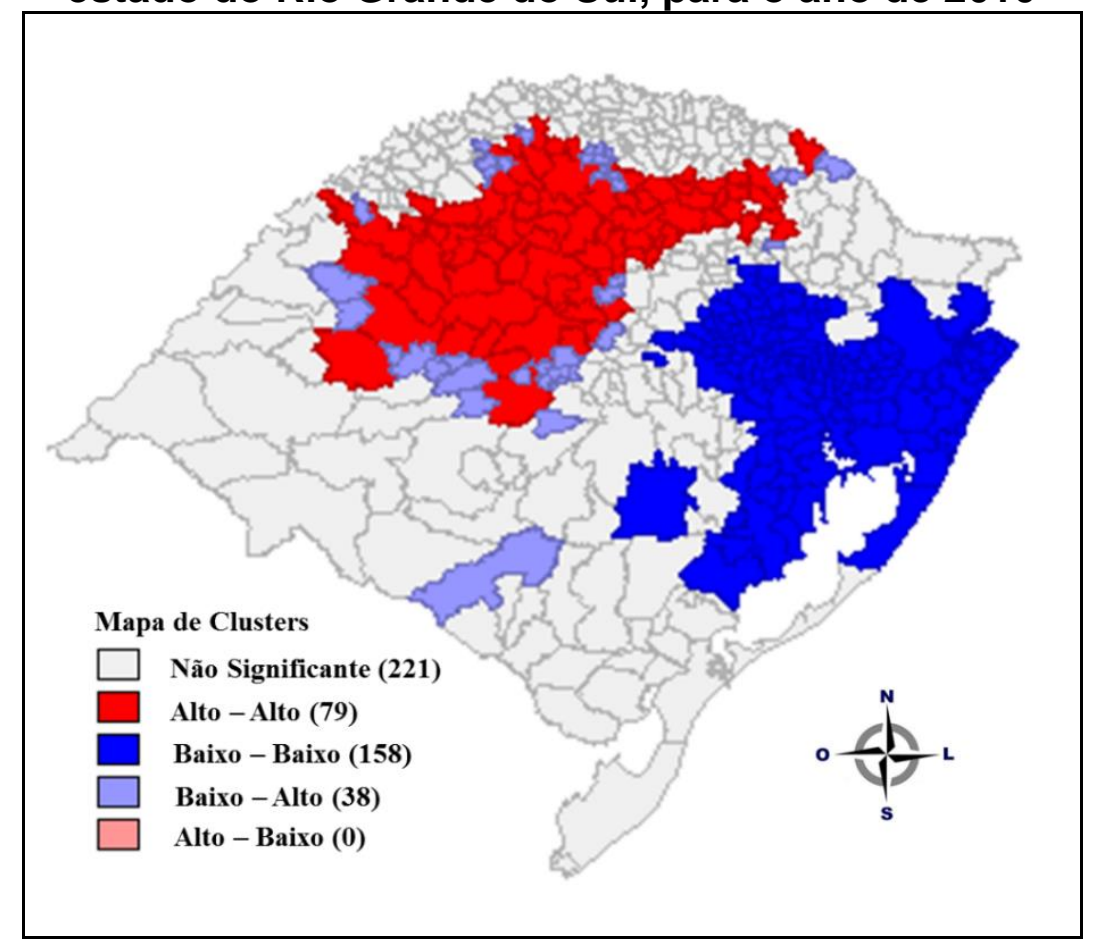

Fonte: Elaboração dos autores.

A análise dos mapas de clusters permitiu verificar o efeito causado pelo boom das commodities na produção de soja no Rio Grande do Sul. No curto-prazo (Figura 7), percebeu-se uma tendência de transbordamento da produção para regiões diversas do estado, ilustrando a tentativa dos produtores de buscarem tirar proveito da alta nos preços das commodities. Após o arrefecimento da suba dos preços (Figura 8), verificou-se um reagrupamento na região mais a norte do estado, indicando que as características espaciais, de fato, influenciam na produção de soja, já que há elevada autocorrelação espacial entre os municípios com grandes VBP.

\section{Considerações finais}

O presente artigo teve como objetivo analisar as alterações proporcionadas pelo forte incremento nos preços das commodities sobre a distribuição espacial da produção da soja no estado do RS, através de análise exploratória de dados espaciais (AEDE), e identificar a formação de clusters.

A análise do índice de Moran Global realizada com quatro critérios de vizinhança validou a hipótese de autocorrelação espacial entre os municípios do estado a 1\% de significância, evidenciando autocorrelação espacial positiva entre os vizinhos, ou seja, municípios com alto valor de produção situam-se próximos a 
outros municípios com VBP elevado, e municípios com baixo VBP estão próximos a outros municípios de igual característica.

A análise exploratória de dados espaciais permitiu que fossem observadas as alterações ocasionadas pelo boom das commodities no que se refere à distribuição espacial da produção de soja no estado. Percebeu-se que, em todos os anos estudados, há dois clusters bem definidos, um alto-alto e um baixo-baixo. O cluster alto-alto obteve variações ao longo do tempo, apresentando espraiamento dos municípios que o integravam para outras regiões do estado no ano que sucedeu o boom e, posteriormente (2010), exibindo um reagrupamento em direção à região em que se encontrava previamente (2000). O cluster baixo-baixo teve redução nos municípios que o integravam logo após o boom, porém, no longo prazo, retornou, praticamente aos mesmos níveis de 2000.

Os procedimentos realizados foram capazes de evidenciar de que forma a distribuição espacial do Rio Grande do Sul reagiu às variações de preços ocasionadas pelo forte aumento nos preços das commodities no que se refere à produção de soja. Através dos recortes analisados, foi possível visualizar os padrões espaciais existentes antes, durante e depois desse evento.

\section{REFERÊNCIAS}

ALICEWEB. Consultas. Disponível em: <http://aliceweb.mdic.gov.br/>. Acesso em: 10 mar. 2018.

ALMEIDA, E. S.. Econometria Espacial Aplicada. 1a.. ed. Campinas: Alínea Editora, 2012.

ALMEIDA, E. S.; Perobelli, F. S. Ferreira, P. Existe convergência espacial da produtividade agrícola no Brasil? Revista de Economia e Sociologia Rural, v. 46, p. 31-52, 2008.

ANSELIN, L.; BERA, A. Spatial Dependence in linear Regression Models with an Introduction to Spatial Econometrics. In: ULLAH, A.; GILLES, D.E. (eds.). Handbook of applied economic statistics, Nova York: Marcel Dekker, p. 237-289, 1998.

ARAÚJO, Massilon J.. Fundamentos de agronegócios. 4. ed. São Paulo: Atlas S.a., 2013.

BANCO CENTRAL DO BRASIL. Anuário Regional, Estatístico do Crédito

Rural. Disponível em: <http://www.bcb.gov.br/pt-br/\#!/n/CREDRURAL>. Acesso em: 11 mar. 2018.

BLACK, Clarissa. O boom de preços de commodities e a economia brasileira nos anos 2000. Dissertação. UFRGS, 2015. Disponível em: < http://www.lume.ufrgs.br/handle/10183/132980>. Acesso em: 12 fev. 2018.

CASTILHOS, Clarisse Chiappini; BRAGANHOLO, Manuela Valim. Consequências preocupantes da expansão acelerada da soja. Carta de Conjuntura. Porto Alegre, p. 7-7. nov. 2014. Disponível em: <http://carta.fee.tche.br/?issue=ano-23-numero-11/>. Acesso em: 10 mar. 2018. 
COMPANHIA NACIONAL DE ABASTECIMENTO. Acompanhamento da safra brasileira de grãos. Brasília: Conab, 2018. Disponível em: <http://www.conab.gov.br/ >. Acesso em: 12 fev. 2018.

DALL'AGNOL, Amélio; LAZAROTTO, Joelsio José; HIRAKURI, Marcelo Hiroshi. Desenvolvimento, Mercado e Rentabilidade da Soja Brasileira. Embrapa Soja, Londrina, abril. 2010. Disponível em: < http://www.cnpso.embrapa.br/download/CT74_eletronica.pdf>. Acesso em: 10 fev. 2018.

DELGADO, Guilherme Costa. A Questão Agrária no Brasil, 1950-2003. In: JACCOUD, Luciana et al. Questão Social e Políticas Sociais no Brasil Contemporâneo. Brasilia: Ipea, 2005. p. 51-90.

Disponívelem:<http://www.ipea.gov.br/agencia/images/stories/PDFs/livros/Livro_Questao_S ocial.pdf>. Acesso em: 11 fev. 2018.

FEIJÓ, Carmem Aparecida; RAMOS, Roberto Luís Olinto (Org.). Contabilidade Social: A nova referência das Contas Nacionais do Brasil. Rio de Janeiro: Elsevier, 2013.

FEIJÓ, Ricardo Luis Chaves. Economia agrícola e desenvolvimento rural. Editora: LTC Grupo Gen. 2011.

FREITAS, Clailton Ataídes de; SÁFADI, Thelma. Volatilidade dos Retornos de Commodities Agropecuárias Brasileiras: um teste utilizando o modelo APARCH. Revista de Economia e Sociologia Rural, v.53, n.2.: FCU, apr./jun. 2015. Disponível em:<http://www.scielo.br/scielo.php?script=sci_arttext\&pid=S0103-20032015000200211> Acesso em: 23 de fev de 2018.

FUNDAÇÃO DE ECONOMIA E ESTATÍSTICA. Indicadores do Agronegócio. Disponível em: <https://www.fee.rs.gov.br/indicadores/agronegocio/exportacoes/destaques-do-mes/>. Acesso em: 14 mar. 2018.

GREMAUD, Amaury Patrick; VASCONCELLOS, Marco Antonio Sandoval; TONETO, Rudinei. Economia Brasileira Contemporânea. 8ae edição. São Paulo: Atlas, 2017.

INSTITUTO BRASILEIRO DE GEOGRAFIA E ESTATÍSTICA. SIDRA. 2018. Disponível em: $<$ https://sidra.ibge.gov.br/home/pms/brasil/>. Acesso em: 20 fev. 2018.

MINISTÉRIO DA INDÚSTRIA, COMÉRCIO EXTERIOR E SERVIÇOS (MDIC). Balança comercial brasileira: Estados. Disponível em:

$<$ http://www.mdic.gov.br/index.php/comercio-exterior/estatisticas-de-comercioexterior/balanca-comercial-brasileira-unidades-da-federacao>. Acesso em: 17 mar. 2018.

MINISTÉRIO DA AGRICULTURA, PECUÁRIA E ABASTECIMENTO (MAPA). Valor Bruto da Produção Agropecuária (VBP). Disponível em:

$<$ http://www.agricultura.gov.br/assuntos/politica-agricola/valor-bruto-da-producaoagropecuaria-vbp>. Acesso em: 05 mar. 2018.

PASIN, Jorge Antonio Bozoti. A Logística de Exportação da Soja em Grãos de Mato Grosso. Bndes, Rio de Janeiro, v. 14, n. 27, p.195-212, jun. 2007. Disponível em: <https://www.bndes.gov.br/SiteBNDES/export/sites/default/bndes_pt/Galerias/Arquivos/conh ecimento/revista/rev2708.pdf>. Acesso em: 10 fev. 2018.

ROCHA, Cláudia Bueno; PARRÉ, José Luiz. Estudo da Distribuição Espacial do Setor Agropecuário do Rio Grande do Sul. Análise Econômica, Porto Alegre, v. 52, n. 27, p.139160, set. 2009. Disponível em: 
<http://seer.ufrgs.br/index.php/AnaliseEconomica/article/view/5159/7457>. Acesso em: 15 mar 2018.

\section{SECRETARIA DE PLANEJAMENTO, GOVERNANÇA E GESTÃO. Atlas}

Socioeconômico. Disponível em: <http://www.atlassocioeconomico.rs.gov.br/inicial>. Acesso em: 28 fev. 2018.

SERIGATI, F. C.. Análise econômica: A macroeconomia da agricultura. Agroanalysis (FGV), v. 33, p. 15-16, 2013. Disponível em <

http://bibliotecadigital.fgv.br/ojs/index.php/agroanalysis/article/viewFile/20751/19485>. Acesso em: 27 mar. 2018.

SILVA, L. N. S.; Borges, M. J.; PARRÉ, J. L. Distribuição Espacial da Pobreza no Paraná. Revista de Economia (Curitiba), v. 39, p. 35-58, 2013.

TRENNEPOHL, Dilson; PAIVA, Carlos Águedo Nagel. A importância da sojicultura para o desenvolvimento da região noroeste do Rio Grande do Sul. Ensaios Fee, Porto Alegre, v. 31, n. 1, p.741-778, jun. 2011. Disponível em:

<https://revistas.fee.tche.br/index.php/ensaios/article/view/2578>. Acesso em: 09 mar. 2018.

VIDIGAL, C. B. R.; PARRE, J. L. Estudo da Distribuição Espacial do Setor Agrícola do Rio Grande do Sul. Análise Econômica (UFRGS), v. 27, p. 139-160, 2009.

VIEIRA FILHO, José Eustáquio Ribeiro. Expansão da Fronteira Agrícola no Brasil: Desafios e Perspectivas. Ipea, Rio de Janeiro, p.1-36, ago. 2016. Disponível em:

<http://repositorio.ipea.gov.br/bitstream/11058/6909/1/td_2223.PDF>. Acesso em: 07 mar. 2018.

WARNKEN, Phil. O futuro da soja no brasil. Política Agrícola, Brasília, v. 9, n. 2, p.1-12, jun. 2000. Disponível em:

<https://seer.sede.embrapa.br/index.php/RPA/article/view/663/617>. Acesso em: 28 fev. 2018.

\section{NOTAS DE AUTOR}

\section{CONTRIBUIÇÃO DE AUTORIA}

Jessica de Lima da Vida Pellenz - Concepção, coleta de dados, análise de dados, elaboração do manuscrito, revisão e aprovação da versão final do trabalho.

Mariza de Almeida - Concepção, coleta de dados, análise de dados, elaboração do manuscrito, revisão e aprovação da versão final do trabalho.

Clailton Ataídes de Freitas - ideias, evolução de metas e objetivos de pesquisa, auxílio na criaçãodo modelo, aquisição do suporte financeiro, revisão e aprovação da versão final do trabalho.

\section{FINANCIAMENTO}

O presente trabalho foi realizado com apoio da Coordenação de Aperfeiçoamento de Pessoal de Nível Superior Brasil (CAPES) e do projeto de pesquisa intitulado PROJETO DE AVALIAÇÃO DOS EFEITOS SPILLOVERS DA PRODUTIVIDADE DA SOJA NO RIO GRANDE DO SUL E NA FRONTEIRA COM SANTA CATARINA da Universidade Federal de Santa Maria.

\section{CONSENTIMENTO DE USO DE IMAGEM}

Não se aplica.

\section{APROVAÇÃO DE COMITÊ DE ÉTICA EM PESQUISA}

Não se aplica.

\section{CONFLITO DE INTERESSES}

Não se aplica

\section{LICENÇA DE USO}

Este artigo está licenciado sob a Licença Creative Commons CC-BY. Com essa licença você pode compartilhar, 
adaptar, criar para qualquer fim, desde que atribua a autoria da obra.

\section{HISTÓRICO}

Recebido em: 24-08-2018

Aprovado em: 10-02-2019 